\title{
FIGURAÇÃO DA CRIANÇA REFUGIADA NA LITERATURA INFANTIL E CONCEPÇÕES DE INFÂNCIA: DOIS MENINOS DE KAKUMA ${ }^{1}$
}

Lígia Regina Máximo Cavalari Menna

Resumo: A fome, a miséria, a guerra, perseguições e violações dos direitos humanos, enfim, questões políticas e sociais de toda ordem, têm obrigado milhares de pessoas a abandonar suas casas, famílias e pátria em busca de refúgio, esperançosas de retornar um dia, ou reconstruir suas vidas em terras distantes, ou simplesmente viver. Segundo a Acnur, (Agência da ONU para Refugiados), em 2020, o número de refugiados no mundo ultrapassou 80 milhões, sendo que apenas $30 \%$ são considerados formalmente como tais, considerando que mais de $4 \%$ ainda não encontraram refúgio, além dos incontáveis mortos durante frustradas tentativas de fuga. Na história, na mitologia e nas artes em geral, antigo é o tema da migração forçada, dos refugiados, pessoas exiladas, perseguidas, vivendo na diáspora, dentre elas muitas crianças, compondo o retrato perverso e atual de uma sociedade doente e em constante ebulição. A literatura está repleta de exemplos em que crianças protagonizam tão dura realidade. Pensando na literatura infantil, nossa área de estudos, levantamos alguns questionamentos: como são figuradas as crianças refugiadas na literatura infantil? Que concepções de infância podemos depreender de narrativas que abordam temas tão sensíveis, histórias de sofrimento, abandono e resiliência? Com o objetivo de refletir sobre tais questões, propomos a análise da obra Dois meninos de Kakuma, de Marie Ange Bordas. Destacamos que a infância é uma construção social, condicionada a questões culturais, filosóficas, econômicas e por muitas vezes religiosas, assim, a partir de uma perspectiva social e histórica, podemos dizer que não existe somente uma infância, mas várias. Como aporte teórico, utilizaremos Marisa Lajolo, Regina Zilberman, Philippe Ariès, Collin Heywood, Carlos Reis e Walter Benjamin.

Palavras-chave: Infância. Refugiados. Figuração. Literatura Infantil.

1 Título em língua estrangeira: "Figuration of the refugee children in children's literature and childhood conceptions: Dois meninos de Kakuma". 
Abstract: Hunger, misery, war, persecutions, and violations of human rights, in short, political and social issues of all kinds, have forced thousands of people to abandon their homes, families and homeland in search of refuge, hoping to return, or to rebuild their lives in distant lands, or just live. According to UNHCR (UN Refugee Agency), in 2020, the number of refugees in the world exceeded 80 million, of which only $30 \%$ are formally considered as such, considering that more than $4 \%$ have not yet found refuge, not to mention the countless deaths during unsuccessful escape attempts. In history, mythology, and the arts in general, ancient is the theme of forced migration, refugees, exiles, persecuted people living in the diaspora, among them many children who live a perverse and current portrait of a sick and constantly boiling society. Literature is full of examples in which children play such a harsh reality. Thinking about children's literature, our area of study, we raised some questions: how are children represented in these narratives arising from such traumatic social issues? What conceptions of childhood can we infer from these stories of suffering, abandonment, and resilience? In order to reflect on these issues, we propose an analysis of the work Dois Meninos de Kakuma, by Marie Ange Bordas. We emphasize that childhood is a social construction, conditioned to cultural, philosophical, economic, and often religious issues, so, from a social and historical perspective, we can say that there is not only one childhood, but several. As a theoretical contribution, we will use Marisa Lajolo, Regina Zilberman, Philippe Ariès, Collin Heywood, Carlos Reis e Walter Benjamin.

Keywords: Childhood. Refugees. Figuration. Children's literature.

\section{Introdução}

Buscando a terra da paz,

Sem bombas estourando,

Atrás de um novo país, Vai crescendo assim o bando A cruzada das crianças, Bertold Brecht

Na história, na mitologia e nas artes em geral, antigo é o tema dos refugiados, dos processos migratórios, forçados 
ou não, e de seus atores: pessoas exiladas, perseguidas, vivendo na diáspora, inclusive em seu próprio país, dentre as quais muitas crianças, compondo um retrato perverso e atual de uma sociedade doente e em constante ebulição.

Como exemplo, dentre muitos outros possíveis, podemos citar o poema "A cruzada das crianças", de Bertold Brecht, cujo pequeno excerto utilizamos em epígrafe. Publicado inicialmente em Histórias de almanaque, de 1948, o poema narra a trágica história de um grupo de crianças polonesas que rondam perdidas em busca de um abrigo, vítimas da Segunda Guerra Mundial, mais uma louca tragédia orquestrada pelos adultos. Durante essa dura peregrinação, encontramos exemplos de desamparo e sofrimento, mas também de amizade e de perseverança entre os pequenos, abandonados pelos adultos, mas esperançosos até seus últimos momentos.

Infelizmente, situações como essas, fraturantes e de grande impacto, ainda são uma constante em nossos dias, estampadas nos jornais, na Internet ou na memória dos sobreviventes, ecoando nas páginas literárias. Segundo a Acnur (Agência da ONU para Refugiados), ao final de 2020, o número de refugiados no mundo ultrapassou os 80 milhões, sendo que $40 \%$ são crianças: mais de 32 milhões. 
Os principais países de origem, em número de pessoas, são Síria, Venezuela, Afeganistão, Sudão do sul e Mianmar e correspondem a $68 \%$ dos refugiados pelo mundo.

Apenas $30 \%$ dessas pessoas são consideradas formalmente como refugiados, e mais de $4 \%$ ainda não encontraram refúgio, sem falar do imensurável número de mortos durante tentativas de fuga e travessias.

Em meio a crises migratórias constantes, é importante ressaltar que os termos migrante e refugiado devem ser compreendidos distintamente. Segundo a Acnur, os refugiados:

São pessoas que estão fora de seu país de origem devido a fundados temores de perseguição relacionados a questões de raça, religião, nacionalidade, pertencimento a um determinado grupo social ou opinião política, como também devido à grave e generalizada violação de direitos humanos e conflitos armados. (ACNUR) ${ }^{2}$

Já os migrantes são aqueles que decidem sair de seus países, principalmente para melhorar de vida, para encontrar suas famílias, para estudar e trabalhar, e não por uma ameaça direta. Para nós tal distinção é tênue, já que "decidir sair" parece-nos um tanto vago, uma vez que não ter acesso à educação, emprego, saúde e moradia de qualidade também é uma forma de violação dos direitos

2 Disponível em: https://www.acnur.org/portugues/quem-ajudamos/refugiados/. Acesso em: 25 maio 2020. 
humanos. Tecnicamente, os migrantes podem voltar a seus países de origem e ainda recebem proteção de seu governo, o que não ocorre com os refugiados.

Para além da distinção de termo, verificamos que longa é a lista de obras literárias que abordam a figura do refugiado em diferentes etapas do processo migratório. Contemporaneamente, por exemplo, podemos citar $A$ memória do mar, de Khaled Hosseini; Hibisco Roxo, de Chimamanda Ngozi Adichie, Perséfolis, de Marjana Satrapi e o Longe de casa: minha jornada e histórias de refugiadas pelo mundo, da mais jovem ganhadora do prêmio Nobel da Paz Malala Yousafzai, sendo as duas últimas protagonizadas por crianças e adolescentes, para citar apenas algumas.

Quanto aos livros direcionados ao público infantil, publicados no Brasil nos últimos anos, elencamos, por exemplo, o já citado $A$ cruzada das crianças, de Bertold Brecht, atualmente publicado em formato para crianças pela editora Pulo do gato, com ilustrações de Carme Solé Vendrell; Nenhum peixe aonde ir, de Marie-Francine Hébert; A viagem, de Francesca Sanna, A menina que abraça o vento, de Fernanda Paraguassu e Suryara Bernardi; O cometa é um sol que não deu certo, de Tadeu Sarmento e Dois meninos de Kakuma, de Marie Ange Bordas; dentre muitos outros, sendo esse último objeto de análise deste artigo. 
Pelo olhar de duas personagens, Geedi e Deng, figurações sintéticas de muitas crianças refugiadas, Marie Ange Bordas retrata o campo de Kakuma, no noroeste do Quênia na África, uma região semiárida e inóspita, entrelaçando texto, fotografias e fotoilustrações.

Kakuma, criado em 1992 como algo provisório para uma emergência latente - acolher refugiados da guerra civil do Sudão, principalmente um batalhão de mais de 20 mil crianças perdidas sem rumo por anos, "os meninos perdidos do Sudão" - ainda existe e se tornou uma "cidade" de refugiados, com escolas, hospital e postos de saúde, abrigando cerca de 200 mil pessoas $^{3}$ de mais de 15 países, como Sudão do Sul, Somália, Burundi, Etiópia, República Democrática do Congo, entre outros.

A partir do exposto, este artigo tem por objetivo verificar as conceções de infância depreendidas da análise da obra Dois meninos de Kakuma, considerando a figuração de crianças refugiadas em uma narrativa ficcional destinada ao público infantil, cuja temática sensível e fraturante reflete experiências reais de sofrimento, desamparo, resiliência e esperança.

3 Mais precisamente, até o fim julho de 2020, foram registrados 196.666 refugiados e solicitantes de asilo no campo de refugiados de Kakuma e no Assentamento integrado de Kalobeyei, um novo anexo, segundo dados da UNHCR-KENYA. Disponível em: https://www. unhcr.org/ke/kakuma-refugee-camp. Acesso em: 20 maio 2021. 
Como aporte teórico, utilizaremos, entre outros, Collin Heywood, Philippe Ariès, Walter Benjamin, Marisa Lajolo, Regina Zilberman, entre outros.

\section{Concepções de infância e a figuração da criança na literatura}

O que distinguiria a infância da vida adulta? Ingenuidade, fragilidade e inocência seriam suas principais marcas? As respostas a essas questões não são tão simples, principalmente se pensarmos que, ao longo da história, tais questionamentos chegaram a ser impensáveis ou mesmo irrelevantes.

Marisa Lajolo sintetiza algumas díspares e curiosas concepções de infância, desde a Idade Média até as teorias de Freud. Para a autora, a partir da questão "o que é infância?", diferentes disciplinas formularam várias respostas:

[...] primeiro vendo a criança como um adulto em miniatura; depois concebendo-a como um ser essencialmente diferente do adulto, depois...Fomos acreditando sucessivamente que a criança é uma tábula rasa, onde se pode inscrever qualquer coisa, ou que seu modo de ser adulto é predeterminado pela sua carga genética, ou ainda que as crianças do sexo feminino já nascem carentes de pênis [...]. (LAJOLO, 1997, p. 228)

Verifica-se, dessa forma, que há uma variedade de caminhos para se definir o que é a infância, em oposição àquilo que se toma por a idade adulta, ora por meio de uma 
perspectiva histórica, ora filosófica, ora psicanalítica, ou até mesmo biológica.

Pelo viés histórico, precisamos considerar que o termo "infância" nem sempre teve a acepção da atualidade. Segundo Philippe Ariès, em História Social da Criança e Família (1981), o mundo medieval ignorava a infância e não percebia uma transição para a idade adulta.

Essa afirmação deve-se ao fato de o autor não ter encontrado representações de crianças no material iconográfico pesquisado, ou, quando as encontrou, lembravam adultos em miniatura, o que o levou a afirmar que, até meados do século XII, havia um desconhecimento da infância ou pelo menos uma acepção divergente da moderna. Ele acrescenta uma certa indiferença aos fatores biológicos, pois a ideia de infância estava mais ligada às relações de poder, mais especificamente a de dependência. O termo petit garçon, por exemplo, era utilizado para designar um serviçal, que não era necessariamente uma criança.

Nesse sentido, nem mesmo os jogos ou os trajes separavam as crianças dos adultos na Idade Média, pois todos jogavam da mesma forma e se vestiam igualmente. O que era visível eram os degraus da hierarquia social, 
ou seja, pessoas de classes sociais diferentes vestiamse de formas diferentes e possuíam seus próprios jogos, independentemente de ser uma criança ou um adulto.

Essa indistinção entre as crianças e os adultos na Idade Média também é confirmada por Dieter Richter, citado por Regina Zilberman:

[...] não havia a "infância": nenhum espaço separado do "mundo adulto". As crianças trabalhavam e viviam junto com os adultos, testemunhavam os processos naturais da existência (nascimento, doença, morte), participavam junto deles da vida pública (política), nas festas, guerras, audiências, execuções etc., tendo assim seu lugar assegurado nas tradições culturais comuns: na narração de histórias, nos cantos, nos jogos. (RICHTER, 1977 apud ZILBERMAN, 2003, p. 36)

Por outro lado, o fato de as crianças participarem das atividades adultas na Idade Média não Ihes dava qualquer privilégio ou poder decisório, segundo o historiador Lawrence Stone: "As crianças eram frequentemente negligenciadas, tratadas brutalmente e até mortas; muitos adultos tratavam-se mutuamente com suspeita e hostilidade; o afeto era baixo e raro [...]" (STONE ,1979, p. 69 apud ZILBERMAN, 2003, p. 36).

Analisando diferentes momentos históricos, Ariès acredita que a maneira de ser das crianças tenha sempre 
encantado as mães e as amas, entretanto eram sentimentos não expressos, como tantos outros.

Somente a partir do século XVII, a criança passou a ser diferenciada do adulto em seus trajes, brincadeiras e jogos, sendo vista como um ser frágil, o qual é preciso proteger, um ser gracioso, que se pode admirar. Essa nova forma de ver a criança não apenas propunha o interesse em educá-la e respeitá-la, como também o de mimá-la, surgindo, assim, um sentimento denominado pelo autor de "paparicação" :Um novo sentimento da infância havia surgido, em que a criança, por sua ingenuidade, gentileza e graça, se tornava uma fonte de distração e de relaxamento para o adulto, um sentimento que poderíamos chamar de paparicação" (ARIÈS, 1981, p. 149, grifos nossos).

Entre os moralistas e educadores do século XVII, teria surgido um outro sentimento da infância em diferentes classes sociais. O apego à infância não se exprimia mais por meio da distração, da brincadeira, mas pelo interesse psicológico e pela preocupação moral. Dessa forma, para esses homens, a infância não era divertida nem agradável, conforme se observa nesta afirmação de um padre jesuíta: "Só o tempo pode curar o homem da infância e da juventude, idades da imperfeição sob todos os aspectos" (GRATIEN,1646 apud ARIÈS,1981, p. 162). 
Com a grande mudança de costumes ocorrida durante o século XVII, surgiu uma farta bibliografia moral e pedagógica e uma nova iconografia religiosa: "uma noção essencial se impôs: a da inocência infantil" (ARIÈS, 1981, p. 136).Além disso, a criança passou a ser vista não somente como um ser inocente, mas também como um ser ignorante, que deveria ser civilizado e educado: "Há dois aspectos do sentimento da infância do século XVII, a inocência que é preciso conservar e a ignorância ou a fraqueza que é preciso suprir ou tornar razoáveis" (ARIÈS, 1981, p. 149).

Eis que surgem e se ampliam escolas e literatura específicas para as crianças, dando início à literatura infantil, assunto vasto que não caberá para o momento.

Outro referencial teórico importante para esse tema é a obra do inglês Colin Heywood, Uma história da infância (2004), que atualiza as pesquisas sobre infância, dialoga com Ariès e muitas vezes o questiona.

Heywood discorda de Ariès quanto ao fato de a infância ser ignorada na Idade Média simplesmente por estar ausente das pinturas. Para ele, de forma semelhante, na Inglaterra durante a idade moderna, as crianças também estiveram ausentes da literatura, aparecendo no máximo como um ser à margem do mundo adulto, não havendo uma relação direta entre 
representação da infância e a sua percepção. O que havia, portanto, não era o desconhecimento, mas uma imprecisão para se definir a infância.

Para o autor inglês, a infância apenas pode ser compreendida como uma construção social, ou seja, os termos "criança" e "infância" seriam compreendidos de formas diferentes, em diferentes épocas e lugares, estando condicionados a questões culturais, filosóficas, econômicas e muitas vezes religiosas.

A partir de uma perspectiva social e histórica, o autor conclui que não existe somente uma infância, mas várias:

Atualmente, no Ocidente, acabamos
realmente por associar a infância, em termos
gerais, a características como inocência,
a vulnerabilidade e a assexualidade,
enquanto pessoas em lugares como,
digamos, as favelas da América Latina ou
regiões devastadas pela guerra da África,
provavelmente não o fariam. (HEYWOOD,
2004, p. 12, grifos nossos)

Apesar da visão generalizada e preconceituosa do autor, a nosso ver, aspectos como etnia, gênero, religião, classe social, contexto histórico e cultural precisam ser levados em conta para se estabelecer uma determinada concepção de infância, estando a criança sujeita a seu tempo, a seu meio cultural e às ideologias vigentes. 
Ao longo da história, para se considerar diferentes concepções de infância em outras épocas, estudiosos têm se baseado em biografias, autobiografias, diários, documentos oficiais, manuais de conduta, iconografia, brinquedos, textos literários para adultos, para crianças, tanto em livros como em jornais e revistas. A partir do século $X X$, outros recursos de observação passam a ser utilizados, como depoimentos gravados e filmados, produções audiovisuais e culturais diversas.

Dentre tantas fontes de pesquisa, consideramos a literatura é um campo riquíssimo para os pesquisadores da infância. Nesse sentido, tomemos as importantes considerações da professora Marisa Lajolo em seu texto "Infância de papel e tinta":

Enquanto formadora de imagens, a literatura mergulha no imaginário coletivo e simultaneamente o fecunda, construindo e desconstruindo perfis de crianças que parecem combinar bem com as imagens de infância formuladas e postas em circulação a partir de outras esferas, sejam estas científicas, políticas, econômicas ou artísticas. (LAJOLO, 1997, p. 228)

Interessante observar como a literatura tanto representa como constrói imagens de crianças em um processo dialógico rico e contínuo, acompanhando as 
tendências gerais de uma sociedade ou mesmo rompendo com padrões pré-estabelecidos.

Durante o Romantismo, por exemplo, há uma visão idealizada da infância como a melhor fase de nossas vidas, a criança como um ser puro e inocente, haja vista os famosos versos do poema Meus oito anos, de Casimiro de Abreu: "Como são belos os dias /Do despontar da existência! / Respira a alma inocência" (ABREU, 1849). Já no Realismo, crianças más, traquinas e mimadas como o pequeno Brás Cubas, de Machado de Assis, dão o tom em muitas obras, colocando a inocência e pureza das crianças em cheque:

Desde os cinco anos merecera eu a alcunha de 'menino diabo'; e verdadeiramente não era outra coisa; fui dos mais malignos do meu tempo, arguto, indiscreto, traquinas e voluntarioso. Por exemplo, um dia quebrei a cabeça de uma escrava, porque me negara uma colher do doce de coco que estava fazendo, e, não contente com o malefício, deitei um punhado de cinza ao tacho, e, não satisfeito da travessura, fui dizer à minha mãe que a escrava é que estragara o doce 'por pirraça'; e eu tinha apenas seis anos. (ASSIS, 2004, p. 32)

No Modernismo, a ênfase recai sobre crianças sofridas, pobres, trabalhadoras como observamos nesses versos do poema "Meninos carvoeiros", de Manuel Bandeira, publicado em 1921 no livro Ritmo dissoluto: 
Eh, carvoero!

Só mesmo estas crianças raquíticas

Vão bem com estes burrinhos descadeirados. A madrugada ingênua parece feita para eles... Pequenina, ingênua miséria!

Adoráveis carvoeirinhos que trabalhais como se brincásseis!

-Eh, carvoero!

Quando voltam, vêm mordendo num pão encarvoado, Encarapitados nas alimárias, Apostando corrida, Dançando, bamboleando nas cangalhas como espantalhos desamparados.

(BANDEIRA, 2007, p. 47)

Há uma nítida analogia entre as crianças raquíticas e os burrinhos descadeirados, uma vez que as crianças passam por um processo de zoomorfização, tão semelhantes aos animais. Uma infância em que trabalho e brincadeira se fundem paradoxalmente. A madrugada é ingênua, a miséria é ingênua, as crianças já não o são.

Poderíamos ainda citar os meninos de Vidas Secas, de Graciliano Ramos, e mesmo as crianças abandonadas e delinquentes, como os meninos de Capitães de areia, de Jorge Amado, só para ficarmos em alguns exemplos, levando-se em conta que dentro de uma mesma estética literária diferentes concepções de infância ainda podem ser observadas. 
A partir do exposto, consideramos que é possível depreendermos diferentes concepções de infância a partir da figuração de uma personagem criança em literaturas de épocas e públicos diversos, levando em conta a ficcionalidade, com pano de fundo real ou ideologicamente construído.

Quando nos referimos à figuração de uma personagem, é preciso enfatizar que esse termo é polissêmico, assim como próprio termo "figura". Para nossas análises, vamos considerar que figura é, segundo Carlos Reis: “[...] toda entidade ficcional ou ficcionalizada que desempenha funções na composição e na comunicação instaurada pelo relato ou que vive acontecimentos nele narrados. A manifestação mais evidente da entidade designada como figura é a personagem [...]" (REIS, 2018, p. 163).

Além da personagem ser a entidade ficcional em maior evidência, a figuração também pode ser observada na instancia do narrador. Na obra que analisaremos, o foconarrativo está em primeira pessoa, por meio de dois narradores-personagens, que tratam ora de si mesmos, ora de outros, levando em conta sua individualidade e seu olhar para as outras personagens. Citando Reis:

A figuração designa um processo ou um conjunto de processos discursivos e metaficcionais que individualizam figuras 
antromórficas localizadas em universos diegéticos específicos, com cujos integrantes aquelas figuras interagem enquanto personagens. (REIS, 2018, p. 164)

Vale acrescentar que a figuração, segundo Reis, é um processo dinâmico, gradual e complexo; não se esgota em um lugar específico do texto, pois vai sendo construída ao longo da narrativa, além do que, não se restringe à descrição e não pode ser confundida simplesmente com a caracterização da personagem.

Consideramos ainda que na literatura infantil a figuração se completa, amplia-se ou mesmo ressignifica-se por meio das ilustrações, assim, texto verbal e não verbal são abordados em um conjunto simbólico esteticamente construído.

\section{Dois meninos de Kakuma}

O livro Dois meninos de Kakuma nasceu, segundo a autora Marie Ange Bordas, de um projeto artístico colaborativo realizado em 2003 no campo de refugiados, com várias oficinas de fotografia, sendo que somente em 2018 o livro viria à tona.

O livro é divido em três partes, uma narrada por Geedi, outra por Deng, dois amigos inseparáveis; e a última de caráter jornalístico, com fotografias, dados sobre a autora, o projeto e o campo de refugiados de Kakuma. A maioria das 
fotografias é em preto e branco (PB), analógicas e tiradas na época do projeto.

As fotoilustrações são compostas por essas fotografias, outras mais atuais cedidas por colegas fotógrafos da autora; e desenhos e esculturas produzidos por crianças participantes do projeto MystArt, que vivem em Kakuma, acrescidas de elementos gráficos e visuais variados, criados por Thorsten Deckler. Em geral, ao lado de uma página com texto verbal há uma outra com uma fotoilustração em grandes proporções. Há ainda três páginas duplas somente com fotografias e fotoilustrações, atribuindo ao livro a predominância da imagem.

Nas fotografias são retratados muitos meninos e meninas, sozinhos ou em grupo, brincando, trabalhando e no ambiente escolar, assim como seus olhos, mãos e pés em destaque. Não há uma representação direta para os protagonistas, entidades ficcionais que sintetizam várias crianças.

O primeiro narrador é Geedi, um menino somali de 12 anos que nasceu no campo de refugiados, vivendo com sua irmã e mãe, que, por chegar ao campo ainda grávida, deu-lhe o nome de "geedi", que língua somali significa "em movimento". Alegre, curioso e sempre atarefado, carrega consigo sonhos e inquietações. Na página dupla que abre 
sua narrativa (Figura 1), destacam-se em close os olhos abertos de um menino, nos quais vislumbramos uma imagem distorcida, provavelmente de algumas pessoas, dentre elas a fotógrafa. O rosto e a imagem panorâmica do campo fundem-se em um corpo único, personagem e espaço são um só. Além de mirar o leitor, os olhos de Geedi abrem-se de Kakuma para o mundo.

Figura 1- Narrativa de Geedi

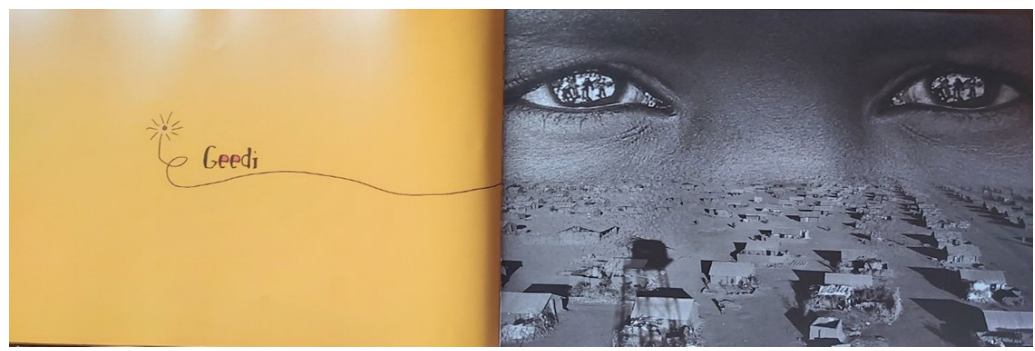

Fonte: Narrativa de Geedi. BORDAS, Marie Ange. Dois meninos de Kakuma/texto e foto ilustração. São Paulo: Pulo do Gato, p. 4-5, 2018.

Tal composição colabora para a figuração da personagem, um menino ansioso por sair do campo, obter novas vivências, mas sempre atento ao seu redor, consciente da situação em que vive, embora não compreenda os motivos dos adultos para tantos conflitos e guerras.

Incialmente, ele nos conta sobre a vida pacata de seus pais na Somália até o dia em que sua mãe e irmã foram obrigadas a fugir da guerra:

Então, um dia, veio a guerra, mataram meu pai, e minha mãe precisou fugir. Só 
teve tempo de pegar algumas coisas e sair correndo, levando minha irmã pela mão. Eu estava bem protegido, dentro de sua barriga. Mamãe tem os olhos brilhantes, mas se afogam de tristeza quando ela relembra a longa jornada até Kakuma. [...] Ela e minha irmã andaram mais de 20 dias, correram perigos e passaram por muitas necessidades. (BORDAS, 2018, p. 8)

Mesmo sem ter vivenciado tal momento, a consciência das provações, miséria e fome pelas quais passaram sua família e muitos outros são reconhecidas pelo jovem narrador.

Em sequência, foca em sua própria narrativa, sua vida cotidiana, repleta de atividades, a escola, os jogos de futebol, as aulas de fotografia, seu desejo de ser fotógrafo, para depois relatar a situação do campo e de alguns dos refugiados:

Bior (professor) foi um dos meninos perdidos do Sudão, como foi chamado o "batalhão" de crianças que fugiu da guerra no Sudão e perambulou durante anos até chegar em Kakuma [...] Muita gente está aqui há mais de 20 anos, e todos os dias continuam a chegar mais e mais refugiados de diferentes países (BORDAS, 2018, p. 19)

A fotoilustração que acompanha esse trecho (Figura 2) é composta por meninos correndo e os desenhos de soldados armados, um a cavalo e dois a pé, como se os estivessem perseguindo. Ao fundo, uma textura que lembra teias de aranha mescla-se à terra seca e rachada da região de Kakuma. 
Figura 2- Os meninos e os soldados

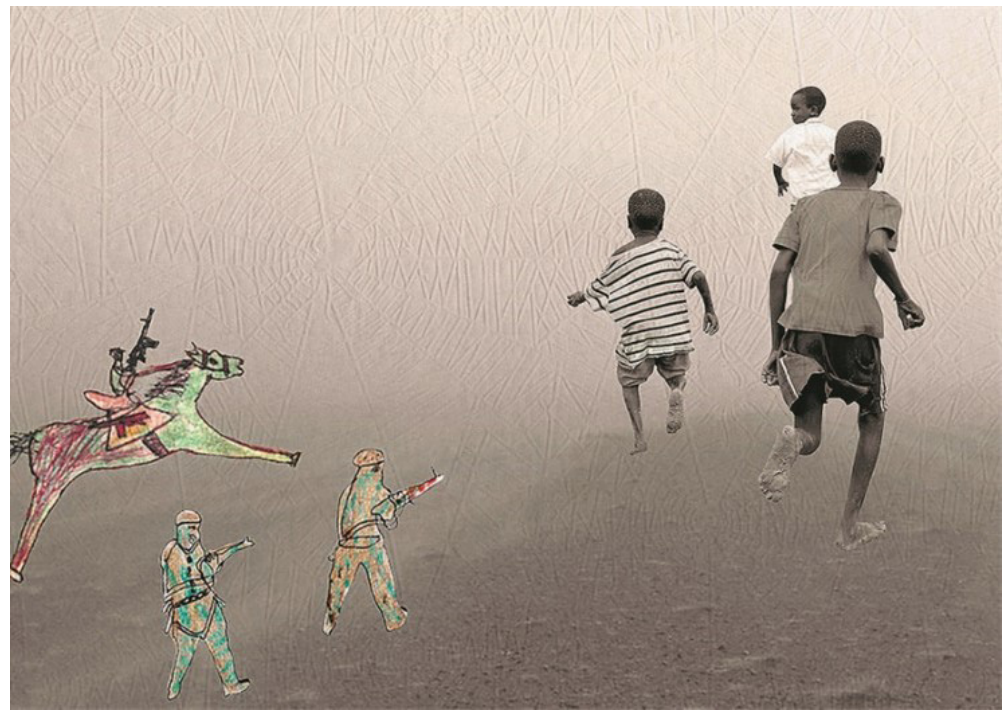

Fonte: Os meninos e os soldados. BORDAS, Marie Ange. Dois meninos de Kakuma/texto e foto ilustração. São Paulo: Pulo do Gato, p. 18, 2018.

Como sabemos, as fotografias foram tiradas no campo e as crianças provavelmente estavam brincando. Já os desenhos foram feitos por várias outras, como registro de suas memórias e vivências. Já a composição proposta por Bordas simula a fuga dos meninos do Sudão, crianças expulsas pelo terror da guerra, assim como aquelas descritas por Brecht, em outro contexto.

A consciência e sabedoria de Geedi denotam uma criança madura, em nada inocente ao universo que a cerca. Ele representa um grupo de jovens fartos dos conflitos provocados pelos adultos: "Os adultos, às vezes, parecem 
esquecer onde estamos e continuam a brigar por motivos que não consigo entender. Desavenças antigas que já deveriam ter acabado lá longe, nas terras de onde vieram. Nós, os mais jovens, estamos cansados de conflitos" (BORDAS, 2018, p. 26).

Há, obviamente, uma incapacidade de resolver tais conflitos ou mesmo de compreendê-los, mas sua opinião manifesta, muito mais sábia do que a de muitos adultos, apresenta-nos um personagem que ainda tem muito que aprender, mas também muito para ensinar.

Geedi termina sua narrativa falando de seu grande amigo Deng e da mais nova refugiada, Noela, uma jovem que chegou ao campo vinda do Sudão, sem os pais, com duas irmãs menores sob sua tutela. Ao se comparar com seus amigos, ele conclui:

Meu passado não dói em mim como em Noela, que decidiu queimar suas fotos de família para tentar esquecer tudo o que perdeu. Ou como em Deng, que ainda hoje guarda nos pés as cicatrizes que ganhou durante a travessia até Kakuma [...] Não quero viver em Kakuma para sempre. Quero crescer e ser dono da minha vida, ter liberdade para escrever minha história em outros lugares. Eu sou Geedi, aquele que nasceu em movimento. (BORDAS, 2018, p. 29) 
Geedi é bastante solidário com seus amigos e, apesar de sua situação, ainda possui seus sonhos e esperanças de liberdade, com os olhos bem abertos, como vimos na fotoilustração que dá início a sua narrativa.

Na abertura para o outro protagonista, Deng, a autora optou por uma fotoilustração bem semelhante (Figura 3), à exceção que os olhos do menino estão fechados, denotando a figuração de uma criança mais ensimesmada, mais reflexiva, aquela que "olha para dentro", fugindo de suas memórias e de uma realidade difícil de enfrentar.

Figura 3 - Narrativa de Deng

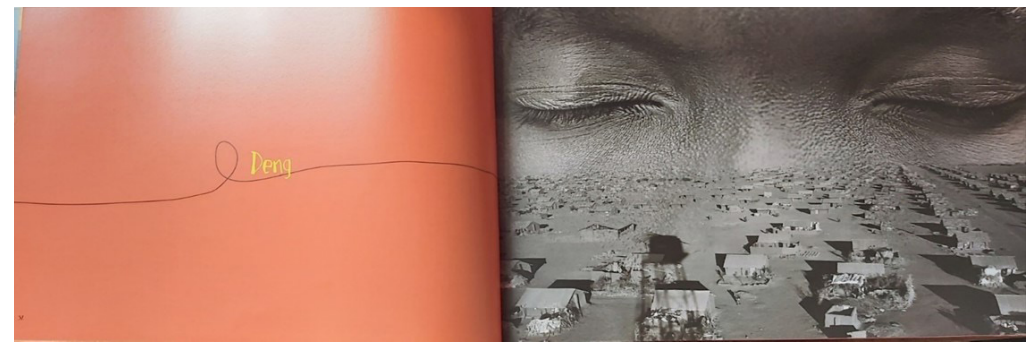

Fonte: Narrativa de Deng. BORDAS, Marie Ange. Dois meninos de Kakuma/texto e foto ilustração. São Paulo: Pulo do Gato, p. 32-33, 2018.

No início de sua narrativa, Deng, um sudanês, cuja idade não é mencionada, nos conta um pouco de sua história, de como sua família morreu na guerra e como ele se refugiou na floreta escura, lembranças intensas e persistentes:

Quando fecho os olhos, ainda vejo meu vilarejo queimando, soldados violentos em cima de seus cavalos, pessoas correndo em 
desespero... Me vejo no esconderijo entre os arbustos da floresta escura, onde fiquei por uma eternidade. Fecho os olhos e escuto tiros, bombas e gritos. Tudo isso não foi mais assustador que o silêncio que veio depois. (BORDAS, 2018, p. 35)

Deng é figurado como uma criança ainda mais sofrida, aquela que vivenciou os delírios da guerra, a fuga pela sobrevivência, com muitas cicatrizes nos pés, como nos relata Geedi, mas que ainda sonha em voltar para sua terra. Ele estuda muito, faz um curso de carpintaria, e adora correr, principalmente como uma forma de "não pensar" e quem sabe apagar suas memórias. Fala também sobre o campo, seus moradores e principalmente de seu amigo Geedi, que adora que ele conte as histórias de quando vivia fora do campo:

$\mathrm{Na}$ beira do rio, depois de nadar, fazíamos bichos de barro, elefantes girafas, bois e muitas vaquinhas. As minhas eram sempre as mais lindas e eu me sentia o menino mais rico do vilarejo com aquele meu rebanho! Aqui em Kakuma, as crianças fazem tanques, helicópteros e armas de barro.

Talvez Geedi tenha sorte de não ter conhecido outra vida, assim ele não sente saudades. Quem sabe eu não pensasse tanto no passado se tivesse uma mãe que se preocupasse comigo, como a mãe de Geedi, que lhe prepara canjeero para o almoço todos os dias. Sinto muita falta de minha mãe. 
Da minha família. Estarão salvos e, em algum lugar? Será que fui o único que sobreviveu? (BORDAS, 2018, p. 35, grifos nossos)

O menino sudanês revela outra forte dor, a da saudade, de uma infância feliz com seus pais, suas brincadeiras, o carinho de sua mãe; e a angústia de não saber se alguém sobreviveu. $\mathrm{O}$ trecho grifado, que relata as brincadeiras das crianças de Kakuma, aparece representado na fotoilustração da página ao lado (Figura 4), com o ângulo da câmera em zenital (crianças vistas de cima), com as poças d'água na cor azul, contrastando com um solo avermelhado e poeirento, um tom lírico em meio a tanta crueza.

Um caminho imaginário, formado por duas linhas paralelas, liga as duas páginas, levando os tanques de guerra de barro, que já fazem parte do imaginário dessas crianças, às vaquinhas da memória afetiva de Deng: dois mundos, duas formas de representação do imaginário infantil.

Figura 4 - Brincando com tanques de guerra

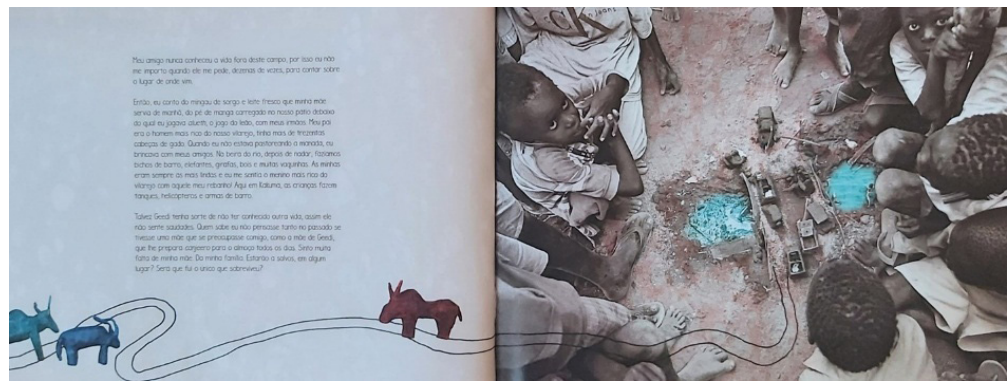

Fonte: Brincando com tanques de guerra. BORDAS, Marie Ange. Dois meninos de Kakuma/texto e foto ilustração. São Paulo: Pulo do Gato, p. 40-41, 2018. 
Ao final de sua narrativa, Deng demonstra esperança em um futuro melhor, sonhador e idealista, como se essa fosse a única forma encontrada para sobreviver.

Se um dia os conflitos cessarem definitivamente em meu país, eu quero voltar e reconstruir minha vida. Talvez no mesmo vilarejo de onde vim. Noela também quer voltar. Podemos ir juntos, um dia, que sabe... Eu poderia construir escolas vilarejos, para todas as crianças, e ela cuidaria dos rebanhos. Pode parecer um sonho distante, eu sei, mas é um bom sonho para sonhar enquanto corro. (BORDAS, 2018, p. 57)

Uma criança amadurecida à força ainda sonha, faz planos para o futuro como um adulto, sintetizando o desejo de muitos refugiados, regressar à sua terra e reconstruir sua vida, algo, infelizmente, muito difícil de acontecer.

Ao final do livro, Marie Ange Bordas diz que manteve contato com boa parte das crianças e jovens com quem conviveu em 2003, escutando suas histórias e ensinandoIhes a fotografar em suas oficinas. Apresenta uma foto de 2018 com alguns deles em que assinala seus destinos à caneta. Alguns migraram para a Malásia, Austrália, Canadá e EUA, alguns permanecem no campo, outros tiveram um destino desconhecido, e apenas um conseguiu voltar para sua terra natal, a Etiópia. 


\section{Considerações Finais}

Vimos nessa breve análise um bom exemplo de como as crianças refugiadas são figuradas em livros dedicados ao público infantil, mas não somente, e cujo tema, tão delicado e fraturante, é apresentado ao leitor de forma sensível e esteticamente bem elaborado.

Geedi e Deng, narradores-personagens, representam muitas dessas crianças, amadurecidas à força, testemunhas de situações traumáticas. O primeiro, aquele que olha para fora, nasceu no campo e observa atentamente a tudo, colocando-se no lugar dos outros, compreendendo suas dores. O segundo, aquele que olha para dentro, tenta apagar suas memórias de dor e saudades, tenta sobreviver. Em comum, além de sua amizade e solidariedade mútua, sonham em sair do campo de refugiados, seguir suas vidas, percorrer novos caminhos.

A concepção de infância retratada nessa obra não é a mesma de boa parte de seus leitores, mas pode levá-los a empatia e a uma visão crítica sobre a situação de tantas crianças refugiadas pelo mundo, tornando-se necessária para a formação dos jovens leitores.

As personagens figuradas não são ignorantes, ingênuas ou fracas; e sua árdua vivência semelhante nos leva a 
questionar se não estamos retornando à concepção de infância medieval, quando as crianças logo eram inseridas no mundo adulto, sem distinções de tratamento, sem poder de decisão, apenas colhendo os frutos dos desvarios dos mais velhos.

Como vimos, a literatura se alimenta do imaginário e a ele alimenta, dialogicamente, algo observável, entre outras instâncias, na figuração das personagens. Na literatura infantil, há de se considerar que essa figuração se completa, amplia-se ou mesmo ressignifica-se por meio das ilustrações, assim, texto verbal e não verbal são abordados em um conjunto simbólico esteticamente construído.

As narrativas de vida, ásperas e impactantes, mesclamse a belas fotoilustrações compostas por fotografias em preto e branco, com um ar de documentário, incomuns em narrativas para o público infantil, mas bastante apropriadas à temática; e desenhos infantis coloridos, alguns leves e alegres, como flores, pássaros, antílopes, vaquinhas, e outros repletos de ambiguidades, cenas de guerra, perseguição violência e morte, imagens que não deveriam fazer parte do imaginário infantil.

Quanto a esse imaginário, citamos Walter Benjamin, para quem a infância possui uma tarefa bem específica, a de introduzir o novo no espaço simbólico: 
Pois a criança pode fazer o que o adulto é completamente incapaz: reconhecer o novo. Para nós, as locomotivas já têm um caráter simbólico, pois as encontramos na infância [...]. Cada infância descobre essas novas imagens para incorporá-las ao patrimônio das imagens da humanidade. (BENJAMIN, 2005, p. 395, tradução livre)

Mas, se cada infância descobre novas imagens, que imagens as crianças refugiadas incorporam ao patrimônio da humanidade?

Não cabe a literatura mudar o mundo, mas ela pode mudar as pessoas que dele fazem parte, dando voz àqueles que não a tem, abordando temas sensíveis, mostrando aos leitores que existem muitas histórias como as dos meninos de Kakuma, crianças adultas e sofridas, mas plenas de esperança de que um futuro melhor ainda é possível, considerando que "esperançar" não é um lugar para espera, mas para ação.

\section{Referências}

ABREU, Casimiro de. Meus oito anos In: CANDIDO, Antonio; CASTELLO, J. Aderaldo. Presença da literatura brasileira. 9. ed. São Paulo: Difel, 1981. ACNUR. Refugiados. Disponível em: https://www.acnur.org/portugues/ quem-ajudamos/refugiados/. Acesso em: 25 maio 2020. ARIÉS, Philippe. História social da criança e da família. Tradução de Dora Flaksman 2. ed. Rio de Janeiro: LTC Livros Técnicos e Científicos Editora S/A, 1981.

ASSIS, Machado de. Memórias póstumas de Brás Cubas. 28. ed. São Paulo: Ática, 2008. 
BANDEIRA, Manuel. Meninos carvoeiros. In: BANDEIRA, Manuel. Meus poemas preferidos. Rio de Janeiro: Ediouro, 2007.

BENJAMIN, Walter. Libro de los pasajes. Madrid: Ediciones Akal, 2005. [Google books].

BORDAS, Marie Ange. Dois meninos de Kakuma/texto e foto ilustração. São Paulo: Pulo do Gato, 2018.

BRECHT, Bertold. A cruzada das crianças. Tradução de Tércio Redondo. Ilustração de Carme Solé Vendrell. São Paulo: Editora Pulo do Gato, 2014. HEYWOOD, Colin. Uma história da infância. Da Idade Média à Época contemporânea no ocidente. Tradução de Roberto Cataldo Costa. São Paulo: Artmed, 2004.

LAJOLO, Marisa. Infância de papel e tinta. In: FREITAS, Marcos César (Org.). História Social da Infância no Brasil. São Paulo: Cortez, 1997. MENNA, Lígia. A literatura infantil além do livro. Rio de Janeiro: Bonecker, 2019.

REIS, Carlos. Dicionário de estudos narrativos. Lisboa: Almedina, 2018. ZELIZER, Viviana A. Pricing the priceless child: the changing social value of children. New York (USA): Basic books,1985.

ZILBERMAN, Regina. A literatura infantil na escola. São Paulo: Global, 2003.

\section{Lígia Regina Máximo Cavalari Menna}

Doutora em Letras na área de Estudos Comparados de Literaturas de Língua Portuguesa (FFLCH-USP).

Pós-doutorado em Letras com o projeto Releituras do maravilhoso: $A$ Rainha da Neve, de Hans Christian Andersen, suas figurações e múltiplos diálogos, sob supervisão da Prof. a Drạ Maria Zilda da Cunha (FFLCH-USP). É docente do Curso de Letras da Universidade Paulista (UNIP) e do Curso de Pós-Lato-Sensu: Língua Portuguesa e Literatura no contexto escolar (UNIP interativa).

Docente colaboradora do Programa de Pós- Graduação do Curso de Letras da FFLCH-USP.

E-mail: mennaligia@gmail.com

Site: http://www.ligiamenna.com.br

Lattes: http://lattes.cnpq.br/6923282866494290

ORCID iD: https://orcid.org/0000-0002-0860-1631 


\section{MISCELÂNEA}

n. 41 (2021): CADERNO SEMINAL - ESTUDOS DE LITERATURA:

Imagens de infâncias em literaturas africanas e/ou das diásporas africanas 
RESENHA DE POR QUE É UM LIVRO MÁGICO?

DE PEDRO PEREIRA DE LOPES; ANGELINA NEVES.

ILUSTRAÇÕES DE MAURICIO NEGRO. MOÇAMBIQUE:

ESCOLA PORTUGUESA DE MOÇAMBIQUE / CENTRO

DE ENSINO E LÍNGUA PORTUGUESA (EPM-CELP), $2020 \quad 624$

ENTREVISTA COM FLÁVIA CÔRTES 636 